\title{
Erratum to what you do not know, you do not recognize... and you do not improve future patient care...particularly in extracorporeal life support (ECLS) patients
}

\author{
Roberto Lorusso ${ }^{1}$, Domenico Corradi ${ }^{2}$ \\ ${ }^{1}$ Cardio-Thoracic Surgery Department, Heart \& Vascular Centre, Maastricht University Medical Centre, Cardiovascular Research Institute \\ Maastricht, Maastricht, The Netherlands; ${ }^{2}$ Department of Medicine and Surgery, Unit of Pathology, University of Parma, Parma, Italy \\ Correspondence to: Prof. Dr. Roberto Lorusso, PhD, FELSO, FEACTS. Cardio-Thoracic Surgery Department, Heart and Vascular Centre, \\ Maastricht University Medical Centre (MUMC), Cardiovascular Research Institute Maastricht (CARIM), P. Debyelaan 25, 6202 AZ Maastricht, The \\ Netherlands. Email: roberto.lorusso@mumc.nl.
}

doi: $10.21037 /$ jtd.2019.11.39

View this article at: http://dx.doi.org/10.21037/jtd.2019.11.39

Erratum to: J Thorac Dis 2019;11:S1930-4.

What you do not know, you do not recognize... and you do not improve future patient care...particularly in extracorporeal life support (ECLS) patients

In the article that appeared on Page S1930-1934, Supplement 15 (September 2019) Issue of the Fournal of Thoracic Disease (ZTD) (1), there is a mistake on the quoted statement. Here, we sincerely apologize for the mistakes.

The title of this editorial comes from a statement ("Wat je kent niet, herken je niet") by Prof. Hein J. J. Wellens, former Head of the Cardiology Department at the Maastricht University Medical Centre, The Netherlands.

Therefore, the correct sentence should have read as follows:

The title of this editorial comes from a statement (“Wat je niet kent, herken je niet”) by Prof. Hein J. J. Wellens, former Head of the Cardiology Department at the Maastricht University Medical Centre, The Netherlands.

The authors regret the error.

\section{References}

1. Lorusso R, Corradi D. What you do not know, you do not recognize... and you do not improve future patient care...particularly in extracorporeal life support (ECLS) patients. J Thorac Dis 2019;11:S1930-4.

Cite this article as: Lorusso R, Corradi D. Erratum to what you do not know, you do not recognize... and you do not improve future patient care...particularly in extracorporeal life support (ECLS) patients. J Thorac Dis 2020;12(3):1157. doi: 10.21037/jtd.2019.11.39 